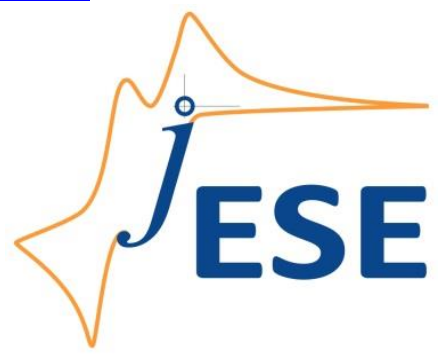

Open Access : : ISSN 1847-9286

www.jESE-online.org

Original scientific paper

\title{
Graphene-modified nickel foam electrode for cathodic degradation of nitrofuranzone: Kinetics, transformation products and toxicity
}

\author{
Ya Ma ${ }^{1,2}$, Yanhong Tang ${ }^{1, 凶}$, Kai Yin², Shenglian Luo², Chengbin Liu², Tian Liu², \\ Liming Yang 2,3
}

${ }^{1}$ College of Materials Science and Engineering, Hunan University, Changsha 410082, P. R. China

${ }^{2}$ State Key Laboratory of Chemo/Biosensing and Chemometrics, Hunan University, Changsha 410082, P. R. China

${ }^{3}$ Key Laboratory of Jiangxi Province for Persistent Pollutants Control and Resources Recycle, Nanchang Hangkong University, Nanchang 330063, P. R. China

Corresponding authors E-mail: ${ }^{凶}$ tangyh@hnu.edu.cn

Received: October 10, 2017; Revised: November 7, 2017; Accepted: November 27, 2017

\begin{abstract}
Simple, efficient, and durable electrodes are highly demanded for practical electrochemical process. In this study, a reduced graphene oxide modified nickel foam electrode (GR-Ni foam) was facilely prepared via one-step cyclic voltammetry electrodeposition of graphene oxide suspension onto the Ni foam. The electrochemical degradation of nitrofuranzone (NFZ, a kind of typical antibiotics) was studied on the GR-Ni foam cathode. The cyclic voltammetry and electrochemical impedance spectra analysis confirmed that presence of GR loading accelerated the electron transfer from the cathode surface to NFZ. With the applied cathode potential of $-1.25 \mathrm{~V}$ (vs. $\mathrm{Ag} / \mathrm{AgCl})$, the removal efficiency of $\mathrm{NFZ}\left(\mathrm{C}_{0}=20 \mathrm{mg} \mathrm{L}^{-1}\right)$ at the GR-Ni foam electrode reached up to $99 \%$ within $30 \mathrm{~min}$, showing a higher reaction rate constant $\left(0.1297 \mathrm{~min}^{-1}\right)$ than $0.0870 \mathrm{~min}^{-1}$ at the Pd-Ni foam and $0.0186 \mathrm{~min}^{-1}$ at the Ni foam electrode. It was also found that the $\mathrm{pH}$, dissolved oxygen and NFZ initial concentration have slight effect on NFZ degradation at the GR-Ni foam electrode. The reactions first occurred at nitro groups $\left(-\mathrm{NO}_{2}\right)$, unsaturated $\mathrm{C}=\mathrm{N}$ bonds and $\mathrm{N}-\mathrm{N}$ bonds to generate furan ring-containing products, and then these products were transformed into linear diamine products. The direct reduction by electrons was mainly responsible for NFZ reduction at the GR-Ni foam electrode. Even after 18 cycles, the removal efficiency of NFZ still reached up to $98 \%$ within $1 \mathrm{~h}$. In addition, the cathodic degradation process could eliminate the antibacterial activity of NFZ. The GR-Ni foam electrode would have a great potential in electrochemical process for treating wastewater containing furan antibiotics.
\end{abstract}

\section{Keywords}

Graphene; Nickel foam; Nitrofuranzone; Electrochemical degradation 


\section{Introduction}

Antibiotics discharged into the environments (e.g., soil and aquatic ecosystems) could increase antibiotic resistance of ecosystems [1-5], bringing about potential threats to aquatic life and even human health. Nitrofuranzone (NFZ) as a low-cost and high-efficiency broad spectrum of antimicrobial agents of nitrofurans is widely used for the treatment of gastrointestinal and dermatological infections in animal husbandry and aquaculture [6]. However, the overuse and misuse of them have led to adverse environmental effects and antibiotics resistance transfer to human pathogenic microbes [7-12]. Because of the microbial resistance of antibiotics, it is very difficult to efficiently remove them using conventional methods (e. g., activated sludge) in wastewater treatment plants. As a result, the water containing nitrofuran antibiotics is discharged frequently into the environment [13-16]. Thus, wastewater containing antibiotics contaminants must be decontaminated before it is discharged into the environment.

A variety of methods including photolysis [17,18], adsorption [19-21], and advanced oxidation process $[22,23]$ have been developed to remove antibiotics. However, photolysis process greatly relies on adequate illumination or involve addition of catalysts, adsorption process is limited due to poor adsorption capacity towards low-concentration antibiotics, and advanced oxidation process involves catalysts or a great deal of reagents that lead to the secondary pollution. Compared to these methods, electrochemical method has been regarded as one of the most effective technology due to its environmental-friendly and high-efficiency properties [24-26]. It is believed that electrochemical reduction process is governed and affected by atomic $\mathrm{H}^{*}$ mediation produced on noble metal catalysts $[27,28]$. However, the limited mining capability and prohibitive cost of noble metals hinder their field application. Furthermore, noble metal catalysts are easily poisoned in the presence of organics and electrochemical process [29,30]. To move the practical application of electrochemical process forward, avoidance of noble metal catalysts is necessary. As a result, developing high-performance electrode materials is crucial for electroreductive reactions in practice.

In this work, we developed a graphene-modified Ni foam electrode (GR-Ni foam), which was facilely synthesized via one-step cyclic voltammetry electrodeposition technique. The as-prepared electrode has the following merits: (i) Ni foam has the advantages including low cost, high stability and porous structure and (ii) graphene has excellent conductivity for fast electron transfer and good adsorption properties towards organic molecules. Ability of this electrode to decompose NFZ was tested using cathodic degradation process. The fate of NFZ during the degradation process was investigated to uncover its destruction pathway. The toxicity of NFZ and the degradation products was evaluated by antimicrobial property. An electrochemical system based on a simple and effective GR-Ni foam electrode could potentially serve for treatment of wastewater containing antibiotics.

\section{Experimental}

Nitrofuranzone (NFZ), citric acid, sodium citrate, palladium chloride $\left(\mathrm{PdCl}_{2}\right)$, sodium sulfate $\left(\mathrm{Na}_{2} \mathrm{SO}_{4}\right)$, sulfuric acid $\left(\mathrm{H}_{2} \mathrm{SO}_{4}\right)$ and tertiary butanol $(t-\mathrm{BuOH})$ were used as received from Aladdin (Shanghai, China). Natural flake graphite with an average particle size of about $50 \mu \mathrm{m}$ was purchased from Shanghai Carbon Co., Ltd. (Shanghai, China), Ni foam (pore density 100 ppi, thickness $1.5 \mathrm{~mm}$ ) was purchased from Shenzhen Lifetion Environmental Protection Equipment Co., Ltd (Shenzhen China), and Nafion 117 solution (5 wt\%) was purchased from Hesen Co., Ltd (Shanghai, China). Ultrapure water was used throughout all the experiments. 
$\mathrm{Ni}$ foam was first ultrasonically cleaned in acetone, $\mathrm{HCl}$ solution and ultrapure water, respectively. Graphite oxide (GO) suspension was synthesized from the flake graphite using modified Hummers method [31]. The graphene modified $\mathrm{Ni}$ foam (GR-Ni foam) electrode was fabricated by cyclic voltammetric electrolysis of $\mathrm{GO}$ suspension $\left(0.3 \mathrm{~g} \mathrm{~L}^{-1}\right)$ using an electrochemical workstation (CHI 660C, Chenhua Co., Ltd., Shanghai, China) with a three-electrode system. Ni foam was applied as the working electrode, Pt foil as the counter electrode, and a saturated calomel electrode (SCE) as the reference electrode, respectively. The potential scan was performed between -1.5 and $0.6 \mathrm{~V}$ at a rate of $50 \mathrm{mV} \mathrm{s}^{-1}$ for 80 cycles. As a control, the Pd-loading $\mathrm{Ni}$ foam (Pd loading amount of $0.135 \mathrm{mg} \mathrm{cm}^{-2}$ ) was prepared through one-step electrodeposition of a mixture solution of $\mathrm{PdCl}_{2}(1 \mathrm{mM})$ and $\mathrm{H}_{2} \mathrm{SO}_{4}(5 \mathrm{mM})$ under magnetic stirring at $-1.0 \mathrm{~V}$ for $60 \mathrm{~s}$. Finally, all the working electrodes were thoroughly washed with ultrapure water and dried at room temperature.

The morphology and composition of as-prepared materials were characterized by field emission scanning electron microscope (SEM, Hitachi S-4800). The crystal structure was characterized using X-ray diffraction equipment (XRD, Cu K $\alpha$ radiation, $\lambda=1.54056 \AA$ ). Raman spectra were measured using a Labram-010 Raman spectrometer with a $632.8 \mathrm{~nm}$ laser. The Pd content in Pd-Ni foam was determined by inductively coupled plasma-optical emission spectrometry (ICP-OES, 5110ICP, Agilent). The cyclic voltammetry (CV), electrochemical impedance spectra (EIS) and electric doublelayer capacitor (EDLC) characterization were performed in a dual chamber equipped with $\mathrm{CHI} 660 \mathrm{C}$ electrochemical workstation using a Pt foil as the counter electrode and SCE as the reference electrode. CV curves were recorded in the scan range between -1.2 and $0 \mathrm{~V}$. The EIS was recorded by applying an alternating current $(A C)$ voltage with $5 \mathrm{mV}$ amplitude in a frequency range 100000$0.01 \mathrm{~Hz}$ at the open circuit voltage. The EDLC characterization was performed between -0.15 and $-0.05 \mathrm{~V}$. All the experiments were performed at room temperature.

A dual-chamber reactor was used for the electroreduction of NFZ, which was separated into a cathode cell $(20 \mathrm{~mL})$ and anode $(20 \mathrm{~mL})$ cell by a cation exchange membrane. The working area of the prepared electrode was $1 \times 1 \mathrm{~cm}^{2}$. A platinum plate $\left(1 \times 1 \mathrm{~cm}^{2}\right)$ was used as the counter electrode, and a silver chloride electrode $(\mathrm{Ag} / \mathrm{AgCl})$ was employed as the reference electrode. The counter electrode was put into the anode chamber, and the working electrode and reference electrode were inserted into the cathode chamber. A constant potential on the cathode was controlled using the amperometric $i$ - $t$ technique by setting up initial $E$ with the electrochemical workstation (CHI660C). The cathode chamber was magnetically stirred at a rate of $1000 \mathrm{rpm}$. Before triggering reaction, the dissolved oxygen in the reactor was removed by bubbling $\mathrm{N}_{2}$ gas.

The concentrations and the decomposed products of NFZ were quantified using a high-performance liquid chromatography (HPLC, Hitachi L-2130, Japan) with an L-2420 UV-vis detector. The mobile phase contained $50 \%$ methanol and $50 \%$ water at a rate of $1 \mathrm{~mL} \mathrm{~min}^{-1}$, the wavelength was $250 \mathrm{~nm}$, and the column temperature was $30^{\circ} \mathrm{C}$. NFZ transformation products were analyzed by a triple quad HPLC-ESI-tqMS (Aglient 1290/6460) and LTQ-Orbitrap Velos Pro (Thermo Fisher Scientific). The positive mode was employed in electrospray ionization. To avoid the possible contamination of equipment, all samples were filtered through $0.22 \mu \mathrm{m}$ filters before the detection.

Luminescent bacteria such as Escherichia coli DH5 $\alpha$ [24] (a typical Gram-negative bacterium) was used to evaluate toxicity of substances. The cells of the strains were harvested at the end of their exponential growth phase. The separated cells were washed with a sterile phosphate buffer solution (PBS) $(50 \mathrm{mM})$ and then inoculated into $24 \mathrm{~mL}$ of 3-fold-diluted Luria-Bertani (LB) medium. To evaluate this non-specific toxicity, the levels of bacteria bioluminescence ( $0.3 \mathrm{~mL}$ bacteria source) were measured in $6 \mathrm{~mL}$ solution of PBS blank, $20 \mathrm{mg} \mathrm{L}^{-1} \mathrm{NFZ}$ and degradation products, respectively. 
This system was loaded into a $50 \mathrm{~mL}$ conical flask and shaken in a shaking incubator with a shaking rate of $180 \mathrm{rpm}$ at $30{ }^{\circ} \mathrm{C}$. The absorbance of optical density at $600 \mathrm{~nm}\left(\mathrm{OD}_{600}\right)$ could reflect the concentration of the living bacteria.

\section{Results and discussion}

\section{Characterizations}

The SEM images of Ni foam and GR-Ni foam are shown in Figure 1(a-b). The surface of bare Ni foam was smooth (Figure 1a), while the surface became rough after depositing graphene sheets (Figure 1b). On the basis of the analysis of Raman spectroscopy (Figure 1c), the two prominent bands observed in GR-Ni foam around 1327 and $1586 \mathrm{~cm}^{-1}$ were assigned to the $D$ and $G$ bands of carbon, respectively, indicating that $\mathrm{GR}$ sheets were successfully deposited onto the Ni foam substrate. The EIS was applied to investigate the electrical properties of the GR-Ni foam and Ni foam cathodes. The typical Nyquist plots are shown in Figure 1d. The GR-Ni foam had a smaller semicircle diameter than bare $\mathrm{Ni}$ foam, indicating that the introduction of $\mathrm{GR}$ increased conductivity and promoted electron transfer [32,33]. Additionally, cyclic voltammetry (CV) can determine the double layer capacitance $\left(C_{\mathrm{dl}}\right)$ which is linearly proportional to effective active surface area $[34,35]$. The CV current responses for the $\mathrm{Ni}$ foam and GR-Ni foam electrodes in the region from -0.15 to $-0.05 \mathrm{~V}$ vs. SCE should be mostly due to the charging of the double layer (Figure S1a and b).

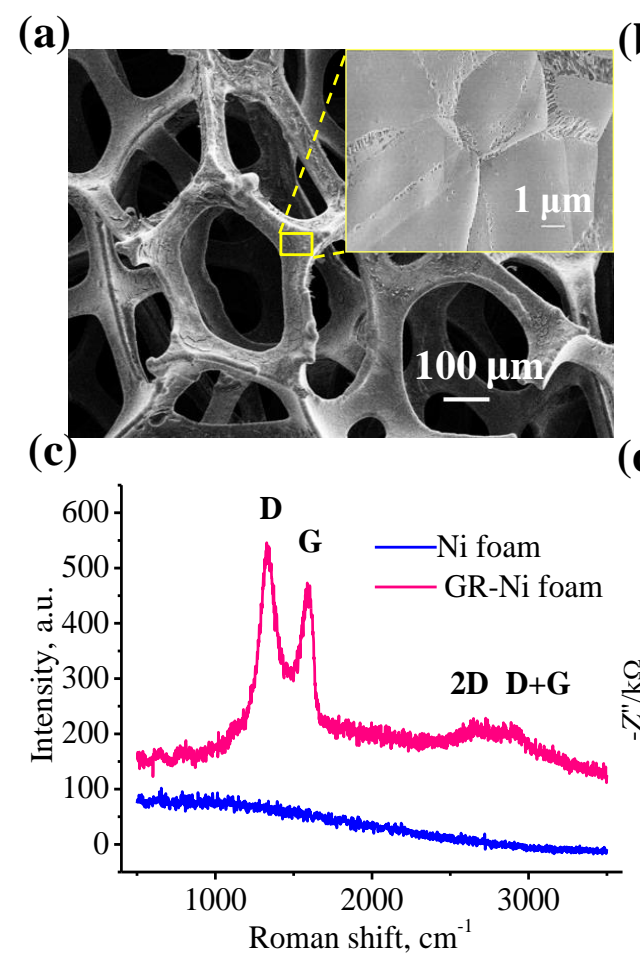

(b)

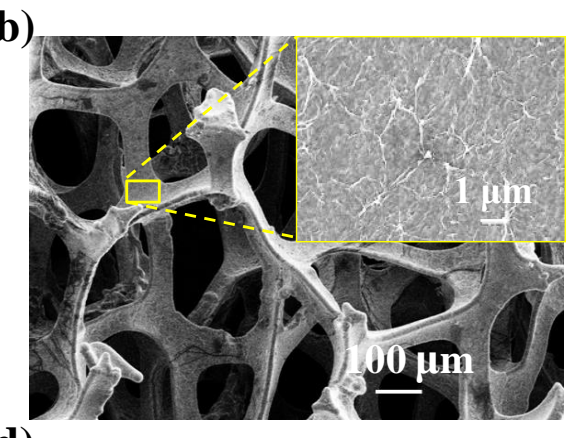

(d)

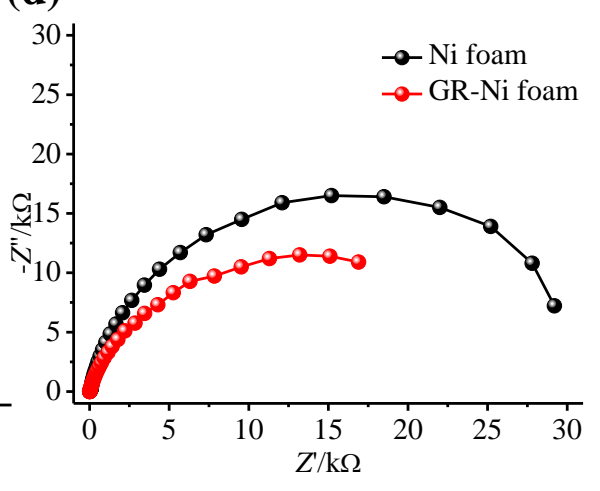

Figure 1. SEM images of (a) Ni foam and (b) GR-Ni foam, (c) Raman spectra of Ni foam and GR-Ni foam electrodes, and (d) Nyquist plots of Ni foam and GR-Ni foam electrodes in $0.1 \mathrm{M} \mathrm{Na}_{2} \mathrm{SO}_{4}$.

The double layer capacitance was estimated by plotting the $\Delta j\left(j_{a}-j_{c}\right)$ at $-0.10 \mathrm{~V}$ against the scan rate (Figure S1c), and the GR-Ni foam had a much larger double-layer capacitance than $\mathrm{Ni}$ foam. The results strongly indicated that the loaded GR could increase the density of catalytically active sites.

As a control, the Pd-Ni foam electrode was prepared through one-step electrodeposition of a $\mathrm{PdCl}_{2}$ solution using $\mathrm{Ni}$ foam as the working electrode. The SEM image showed that dendritic Pd 
particles lay on the surface of $\mathrm{Ni}$ foam (Figure S2). The XRD result confirmed the existence of metallic $\mathrm{Pd}$ (Figure S3). The content of Pd in Pd-Ni foam was $9.4 \mathrm{mg} / \mathrm{g}$ determined by ICP-OES analysis.

\section{NFZ degradation on the prepared electrodes}

The characteristic shape of cyclic voltammograms (CV) is a result of the potential which is dependent on the changes in surface concentrations of redox system and simultaneous diffusion processes [36]. The CV tests were applied for the reduction of NFZ at different electrodes (Figure 2a). In the presence of NFZ, both, the $\mathrm{Ni}$ foam and the GR-Ni foam showed characteristic reduction peak of NFZ at $-0.95 \mathrm{~V}$ (peaks $\mathrm{c}_{1}$ and $\mathrm{a}_{2}$ ) [24,26,37]. In addition, there appeared another reduction peak of NFZ at $-0.60 \mathrm{~V}$ (peak $a_{1}$ ) for the GR-Ni foam. This result indicated that NFZ reduction occurred on the GR-Ni foam at a smaller potential than on the $\mathrm{Ni}$ foam, which could probably be attributed to the reduction of overpotential due to introduction of GR. Additionally, there was an oxidation peak at about $-0.50 \mathrm{~V}$. Similar CV behaviors were observed during the reduction of nitroaromatics nitrobenzene and chloramphenicol [38-40] and attributed to the reversible reactions of nitroso and hydroxylamino intermediates. In contrast, the GR-Ni foam did not show any current peak in the absence of NFZ.
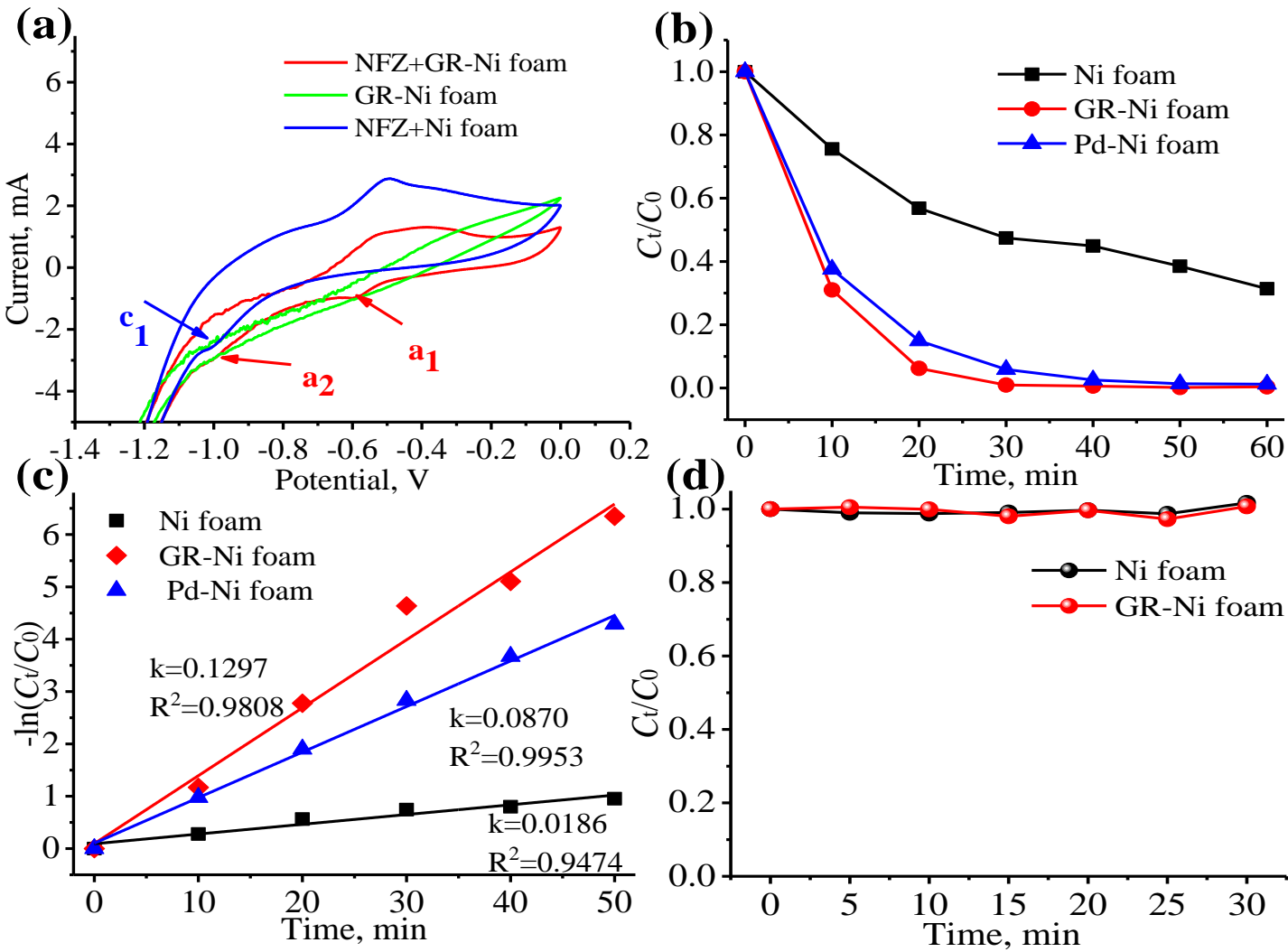

Figure 2. (a) Cyclic voltammograms (vs. $\mathrm{Ag} / \mathrm{AgCl}, 0.1 \mathrm{M} \mathrm{Na}_{2} \mathrm{SO}_{4}, 20 \mathrm{mg} \mathrm{L}^{-1} \mathrm{NFZ}, \mathrm{pH}=4.28$ ), (b) degradation efficiency, (c) degradation kinetics of $\mathrm{NFZ}$ at $-1.25 \mathrm{~V} v \mathrm{vs} . \mathrm{Ag} / \mathrm{AgCl}$, and (d) adsorption of NFZ without bias potential.

The performances of different ( $\mathrm{Ni}$ foam, GR-Ni foam, and Pd-Ni foam) electrodes for removal of $\mathrm{NFZ}$ were determined under the same experimental condition $\left(0.1 \mathrm{M} \mathrm{Na}_{2} \mathrm{SO}_{4}\right.$ solution, $\mathrm{pH} 4.28$, initial NFZ concentration of $20 \mathrm{mg} \mathrm{L}^{-1}$, and applied potential of $-1.25 \mathrm{~V} \mathrm{vs}$. Ag/AgCl) (Figure $2 \mathrm{~b}$ ). Only $53 \%$ NFZ was degraded on the bare Ni foam electrode within $30 \mathrm{~min}$, while the removal efficiency of NFZ on the GR-Ni foam reached up to $99 \%$ what was higher than on the Pd-Ni foam (94\%) within $30 \mathrm{~min}$. The results indicate that the GR-Ni foam would seriously compete with noble metals (e.g. 
Pd)-based electrocatalysts for electrocatalytic degradation of nitrofuran antibiotics. The degradation of NFZ followed a pseudo-first order kinetic model, $-\ln \left(C_{t} / C_{0}\right)=k t+b$, where $t$ is the reaction time $(\min ), k$ is the reaction rate constant $\left(\mathrm{min}^{-1}\right), b$ is a constant, and $C_{t}$ and $C_{0}$ are the NFZ concentrations $(\mu \mathrm{M})$ at times of $t=t$ and $t=0$, respectively. The reaction rate constants $(k)$ of NFZ were $0.1297 \mathrm{~min}^{-1}$ (coefficient $R^{2}=0.9808$ ) for the GR-Ni foam and $0.087 \mathrm{~min}^{-1}\left(R^{2}=0.9953\right.$ ) for the $\mathrm{Pd}$-Ni foam, which were 6.97 and 4.68 times higher than $0.0186 \mathrm{~min}^{-1}\left(R^{2}=0.9474\right)$ for the Ni foam, respectively (Figure $2 \mathrm{c}$ ). Figure $2 \mathrm{~d}$ showed that the adsorption basically did not contribute to the removal of NFZ.

\section{Effect of different parameters}

The influence of different experimental parameters such as cathode potential, initial concentration, solution $\mathrm{pH}$ and dissolved oxygen on electrochemical removal efficiency of NFZ on the GR-Ni foam was also investigated (Figure 3). The degradation rate markedly increased with cathode potential from -0.35 to $-1.25 \mathrm{~V}$ (vs. $\mathrm{Ag} / \mathrm{AgCl}$ ) (Figure 3a).
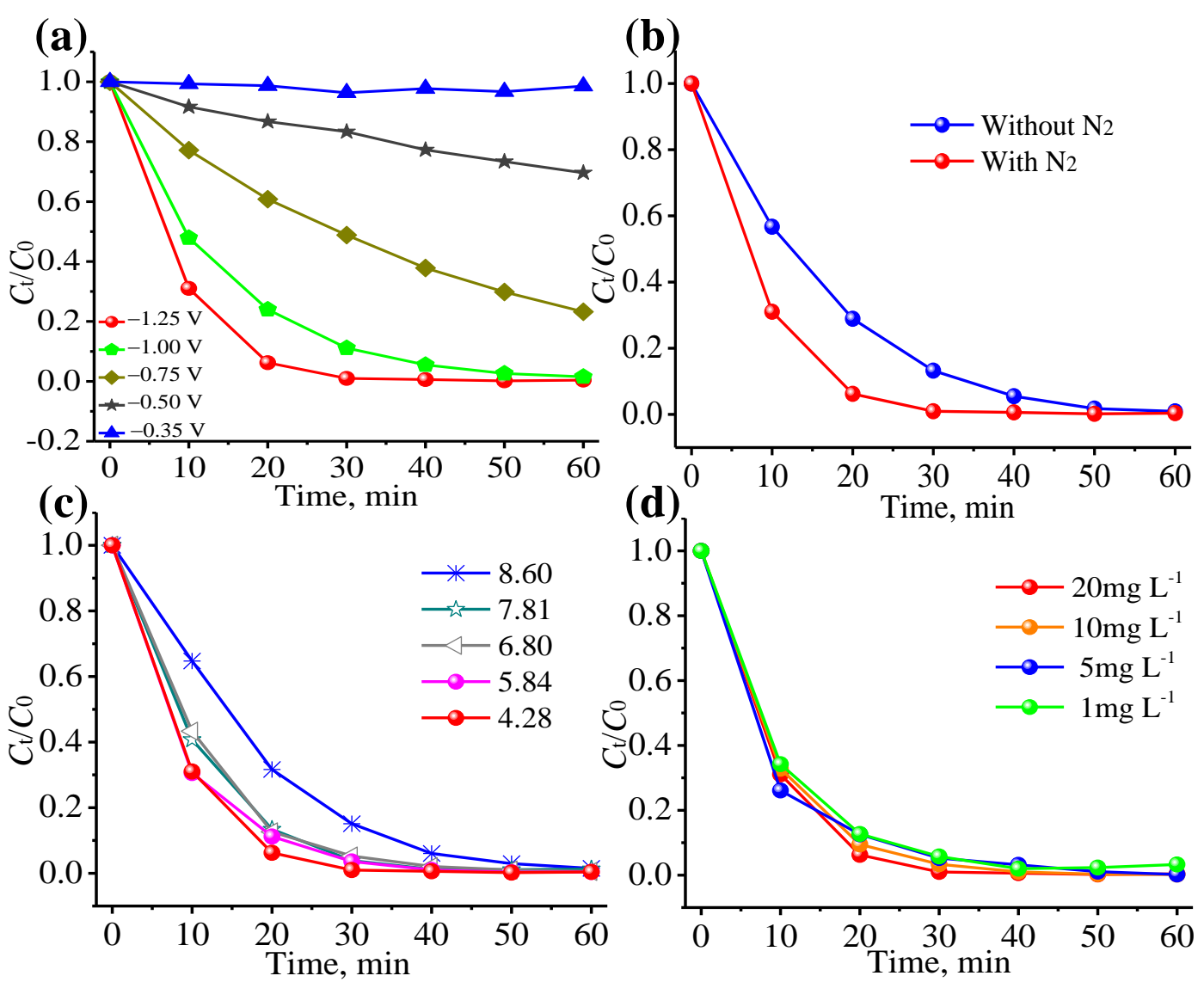

Figure 3. Effect of different experimental parameters on reduction of NFZ on GR-Ni foam cathode:

(a) potential ( $\left.0.1 \mathrm{M} \mathrm{Na}_{2} \mathrm{SO}_{4}, 20 \mathrm{mg} \mathrm{L}^{-1} \mathrm{NFZ}, \mathrm{pH} 4.28\right)$, (b) dissolved oxygen $(-1.25 \mathrm{~V} \mathrm{vs}$. $\mathrm{Ag} / \mathrm{AgCl}$,

$\left.0.1 \mathrm{M} \mathrm{Na}_{2} \mathrm{SO}_{4}, 20 \mathrm{mg} \mathrm{L}^{-1} \mathrm{NFZ}, \mathrm{pH} 4.28\right)$, (c) solution $\mathrm{pH}\left(-1.25 \mathrm{~V}\right.$ vs. $\mathrm{Ag} / \mathrm{AgCl}, 0.1 \mathrm{M} \mathrm{Na}_{2} \mathrm{SO}_{4}, 20 \mathrm{mg} \mathrm{L}^{-1} \mathrm{NFZ}$ ), and (d) initial NFZ concentration (-1.25 V vs. $\left.\mathrm{Ag} / \mathrm{AgCl}, 0.1 \mathrm{M} \mathrm{Na}_{2} \mathrm{SO}_{4}, \mathrm{pH} 4.28\right)$.

More negative cathode potential could produce more available electrons leading to higher efficiency in NFZ reduction. NFZ was nearly completely degraded at the applied potential of $-1.25 \mathrm{~V}$ within $30 \mathrm{~min}$. The NFZ degradations were fitted to the pseudo-first reaction kinetics with rate constant $\mathrm{k}$ of $0.0060 \mathrm{~min}^{-1}\left(R^{2}=0.9904\right), 0.0240 \mathrm{~min}^{-1}\left(R^{2}=0.9996\right), 0.0728 \mathrm{~min}^{-1}\left(R^{2}=0.9999\right)$ and $0.1297 \mathrm{~min}^{-1}\left(R^{2}=0.9808\right)$ at $-0.5,-0.75,-1.0$ and $-1.25 \mathrm{~V}$, respectively (Figure S4). 
It has already been reported that dissolved oxygen could compete with the contaminant for both the electrons and atomic $\mathrm{H}^{*}$ on the cathode surface, suppressing thus the target contaminant reduction $[27,41]$. By purging the solution with $\mathrm{N}_{2}$, the dissolved oxygen was removed. The degradation of NFZ on the GR-Ni foam electrode was studied with and without $\mathrm{N}_{2}$ sparging (Figure $3 \mathrm{~b}$ ). It was observed that the dissolved oxygen had slight effect on NFZ degradation. In addition, NFZ degradation was promoted by decreasing pH from 8.60 to 4.28 (Figure 3c). The generation of atomic $\mathrm{H}^{*}$ is favored in acid solutions, therefore acidic solution facilitates the reduction process by consuming $\mathrm{H}^{*}$ [41-43]. Even so, NFZ degradation efficiency reached up to $83 \%$ at $\mathrm{pH} 8.60$ within $30 \mathrm{~min}$, suggesting that the GR-Ni foam electrode could be used in a wide range of $\mathrm{pH}$ for NFZ degradation. Also, the NFZ degradation slightly increased with increasing initial concentration of NFZ and the degradation efficiency still reached approximately $90 \%$ within 30 min when the initial concentration of NFZ was as low as $1 \mathrm{mg} \mathrm{L}^{-1}$ (Figure 3d).

It is clearly seen that the GR-Ni foam electrode is feasible to work in practical wastewater with different $\mathrm{pH}$, dissolved oxygen and NFZ concentration.

\section{Transformation pathway and proposed degradation mechanism of NFZ}

The degradation products of NFZ on different (Ni foam, GR-Ni foam and Pd-Ni foam) electrodes were measured using LC/MS. The extraction ion chromatogram (EIC) for the detection of these products is shown in Figure S5-S7. Three furan ring-containing products and two linear chain terminal products were detected in the three electrode systems. The furan ring-containing products were (5-nitro-2-furyl) methanamine (NFM), (5-amino-2-furyl)methylene-hydrazinecarboxamide $(\mathrm{AMH})$ and (5-hydroxyamino-2-furyl)methyl-hydrazinecarboxamide $(\mathrm{HMH})$, corresponding to $\mathrm{m} / \mathrm{z}$ $[\mathrm{M}+\mathrm{Na}]^{+}$of 165, 191 and 209, respectively. The linear chain terminal products were 5-aminopentanamide (APA) and 5-hydroxycadaverine ( $\mathrm{HOC}$ ), corresponding to $\mathrm{m} / \mathrm{z}[\mathrm{M}+\mathrm{Na}]^{+}$of 139 and 141 , respectively. The $\mathrm{Na}^{+}$was from $\mathrm{Na}_{2} \mathrm{SO}_{4}$ electrolyte. The transformation pathway of degradation products was illustrated in Scheme 1 . The reactions first occurred at nitro groups $\left(-\mathrm{NO}_{2}\right)$, unsaturated $\mathrm{C}=\mathrm{N}$ bonds and $\mathrm{N}-\mathrm{N}$ bonds to obtain HMA, NFM and AMH products, and then these products were transformed into linear APA products which were finally reduced to HOC.

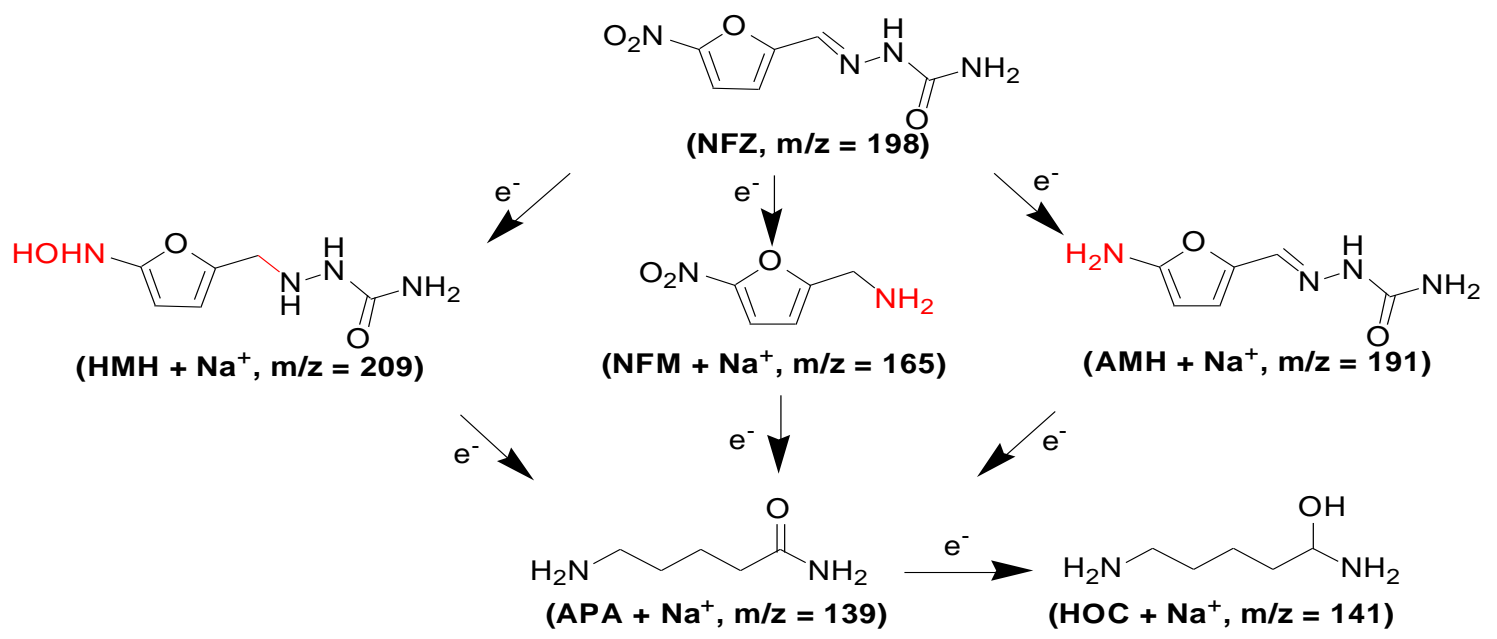

Scheme 1. Transformation pathway of degradation products

It is believed that electrocatalytic reduction of organic pollutants involves direct electron transfer reduction and atomic $\mathrm{H}^{*}$-mediated reduction [41-43]. Tertiary butanol ( $\left.t-\mathrm{BuOH}\right)$ as a scavenger of $\mathrm{H}^{*}$ [44] was used to study NFZ degradation. The $t$ - $\mathrm{BuOH}$ addition $(0,2$ and $5.0 \mathrm{mM})$ did not show effect on NFZ reduction over bare $\mathrm{Ni}$ foam, indicating a direct electron transfer reduction 
(Figure 4a). In contrast, only at a high t-BuOH concentration of $5.0 \mathrm{mM}$, the NFZ reduction on GR-Ni foam electrode was influenced (Figure $4 \mathrm{~b}$ ). Even so, the removal efficiency of NFZ still achieved $88.7 \%$ within $30 \mathrm{~min}$ at $5.0 \mathrm{mM} \mathrm{t}$-BuOH. It was reported that hydrogen produced in electrochemical process could be adsorbed on GR and subsequently activated to atomic $\mathrm{H}^{*}$ [45-47]. It can be inferred that the produced atomic $\mathrm{H}^{*}$ may be in part responsible for NFZ reduction. The results indicated that direct electron transfer reduction played a crucial role in NFZ reduction on the GR-Ni foam. Expectedly, a significant inhibition of NFZ reduction was observed at the Pd-Ni foam in the presence of $t$ - $\mathrm{BuOH}$ (Figure 4c). Pd is well-known to have the unique property of activating protons to atomic $\mathrm{H}^{*}$ and subsequently adsorbing atomic $\mathrm{H}^{*}[48,49]$. Therefore, the reduction of NFZ at the Pd-Ni foam mainly proceeded via $\mathrm{H}^{*}$ mediation.

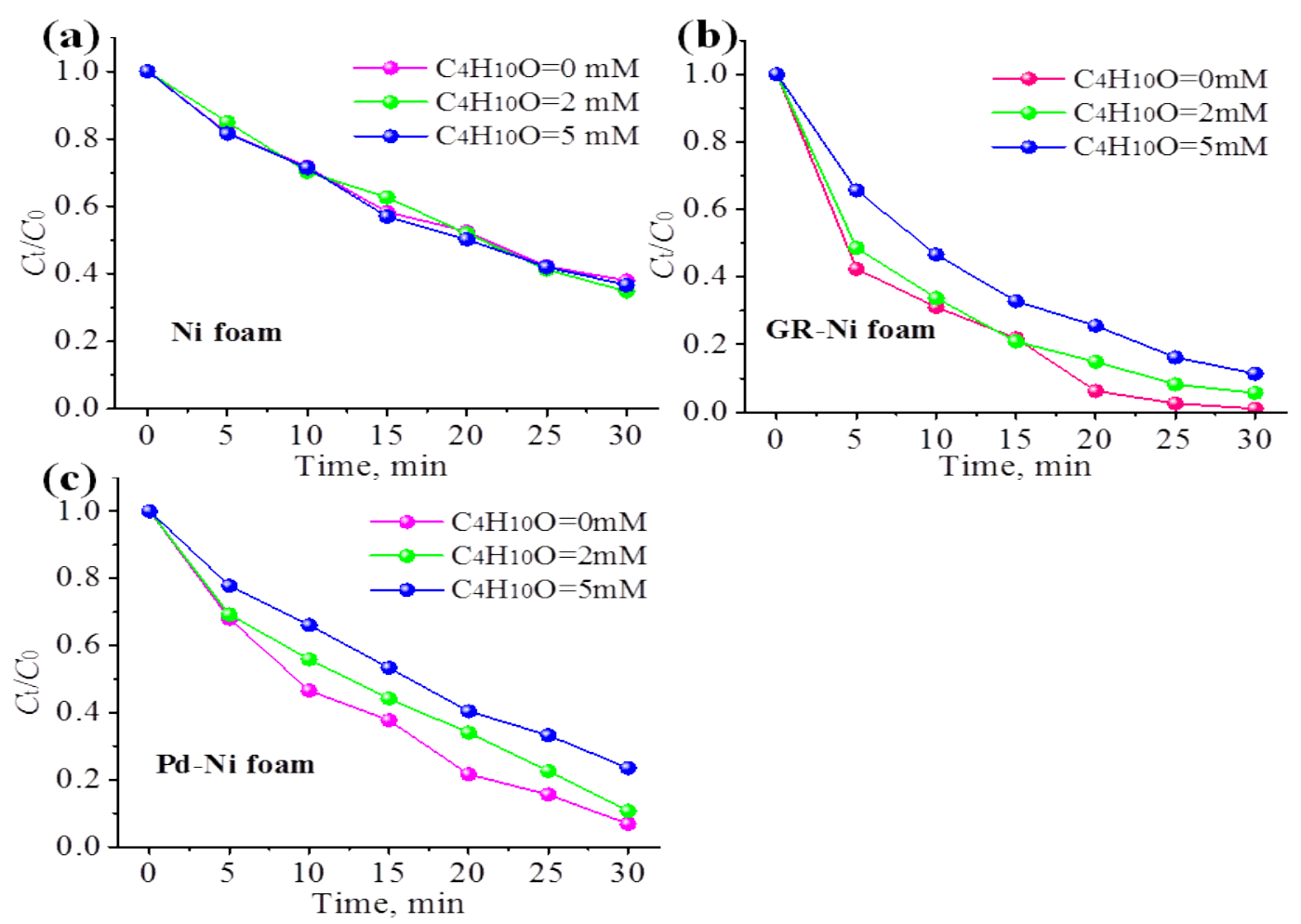

Figure 4. Effect of $t-B u O H(0,2$ and $5 \mathrm{mM}$ ) on NFZ reduction on (a) Ni foam, (b) GR-Ni foam, and (c) Pd-Ni foam electrodes (-1.25 V vs. Ag/AgCl, $0.1 \mathrm{M} \mathrm{Na}_{2} \mathrm{SO}_{4}, 20 \mathrm{mg} \mathrm{L}^{-1} \mathrm{NFZ}, \mathrm{pH}=4.28$ ).

The furan ring-containing products at different electrodes were further quantified using HPLC with UV-vis detector (Figure S8). The linear APA and HOC products could not be quantified using HPLC due to lack of UV-vis absorption. The results are shown in Figure 5. It was found that the transformation products were generated rapidly from the start on the GR-Ni foam electrode, indicating fast reaction kinetics. After approximately $50 \mathrm{~min}$, the concentrations of these products decreased, what is indicative of the further reduction to linear APA and HOC products. In addition, concentrations of the products increased monotonically on the Ni foam electrode, suggesting a limited deep degradation to linear APA and HOC products. It was also seen that after $60 \mathrm{~min}$, although the removal efficiency of NFZ on the Pd-Ni foam electrode reached almost $100 \%$ (Figure $2 \mathrm{~b}$ ), the concentrations of the transformation products were lower than those for the $\mathrm{Ni}$ foam and GR-Ni foam electrodes. The results indicated that the furan ring-containing transformation products were more easily reduced to linear APA and HOC products using the Pd-Ni foam electrode with the aid of atomic $\mathrm{H}^{*} .4$ 

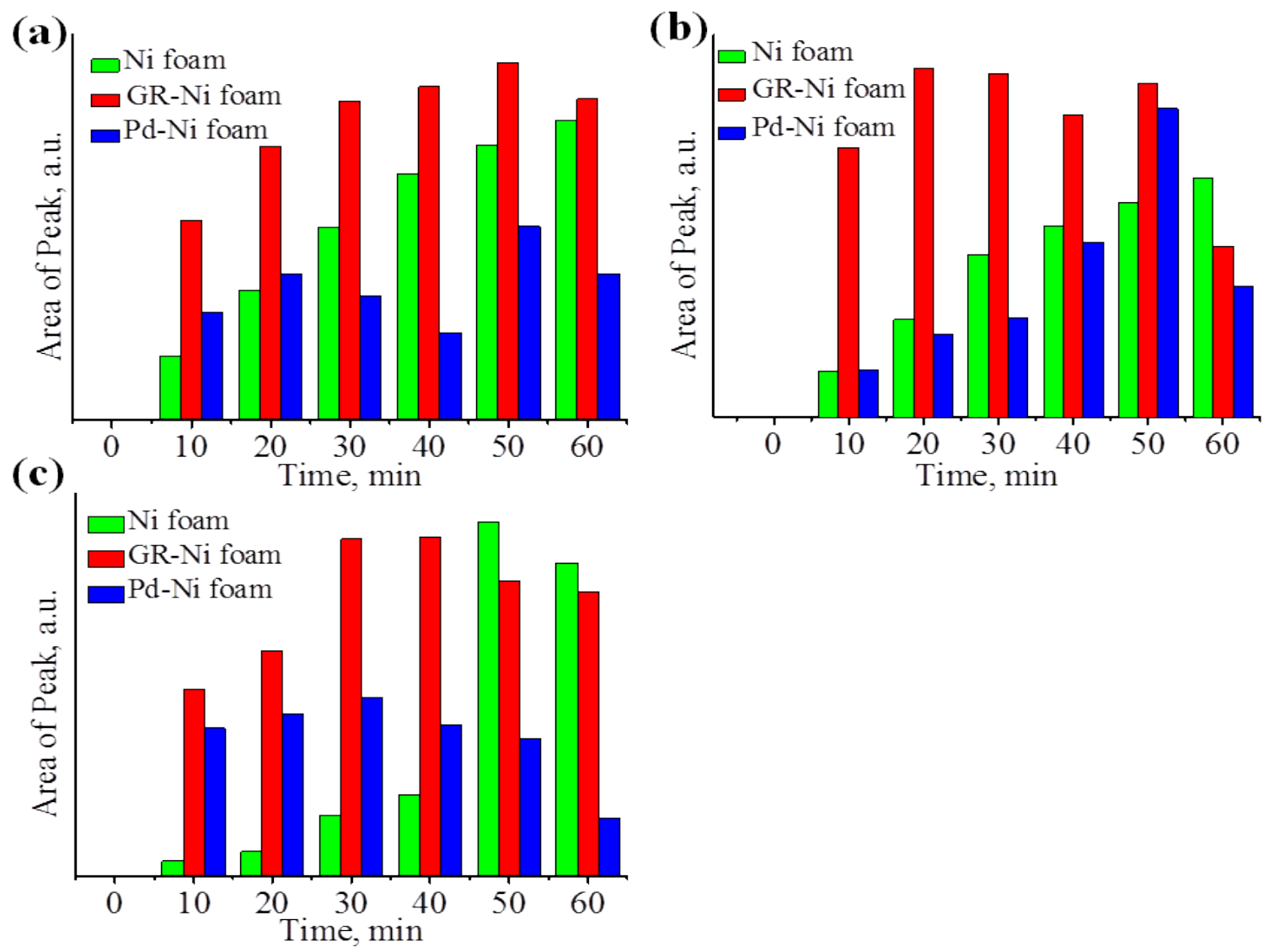

Figure 5. NFZ degradation product concentrations of (a) NFM, (b) $A M H$, (c) $H M H$ on Ni foam, GR-Ni foam and Pd-Ni foam electrodes (-1.25 V vs. Ag/AgCl, $0.1 \mathrm{M} \mathrm{Na}_{2} \mathrm{SO}_{4}, 20 \mathrm{mg} \mathrm{L}^{-1} \mathrm{NFZ}, \mathrm{pH}$ 4.28).

Toxicity assessment of degradation products

E. coli $\mathrm{DH} 5 \alpha$ (a typical Gram-negative bacterium) luminescent bacteria is commonly used to evaluate the toxicity of substances. The antibacterial activity assay was performed using $E$. coli $\mathrm{DH} 5 \alpha$ (Figure 6a), which was reflected by the optical density of the bacterial strains at $600 \mathrm{~nm}\left(\mathrm{OD}_{600}\right)$. The growth of E. coli DH5 $\alpha$ was nearly completely inhibited in the presence of $20 \mathrm{mg} \mathrm{L}^{-1} \mathrm{NFZ}$. In contrast, in the presence of terminal degradation products, the growth of $E$. coli $\mathrm{DH} 5 \alpha$ was slightly inhibited and then returned to normalization after $10 \mathrm{~h}$. Generally, after the nitro group reduction, heterocyclic amine products were less toxic and considerably easier to be mineralized by aerobic bacteria than the nitro group containing antibiotics [50]. So, it can be stated that the electrochemical treatment of wastewater containing NFZ using the GR-Ni foam electrode is efficient to reduce the risk of adverse environmental effect.

\section{Electrode durability}

The durability of electrodes is crucial for practical application of electrochemical process. To evaluate the durability of the GR-Ni foam electrode, electrocatalytic reduction of NFZ was performed after 18 cycles (each cycle time was $1 \mathrm{~h}$ ) (Figure 6b). Significantly, in the $18^{\text {th }}$ cycle, the removal efficiency of NFZ still reached up to $98 \%$, being nearly the same as in the first cycle. The results indicated that the GR-Ni foam electrode was very stable, showing a great potential of practical application. 

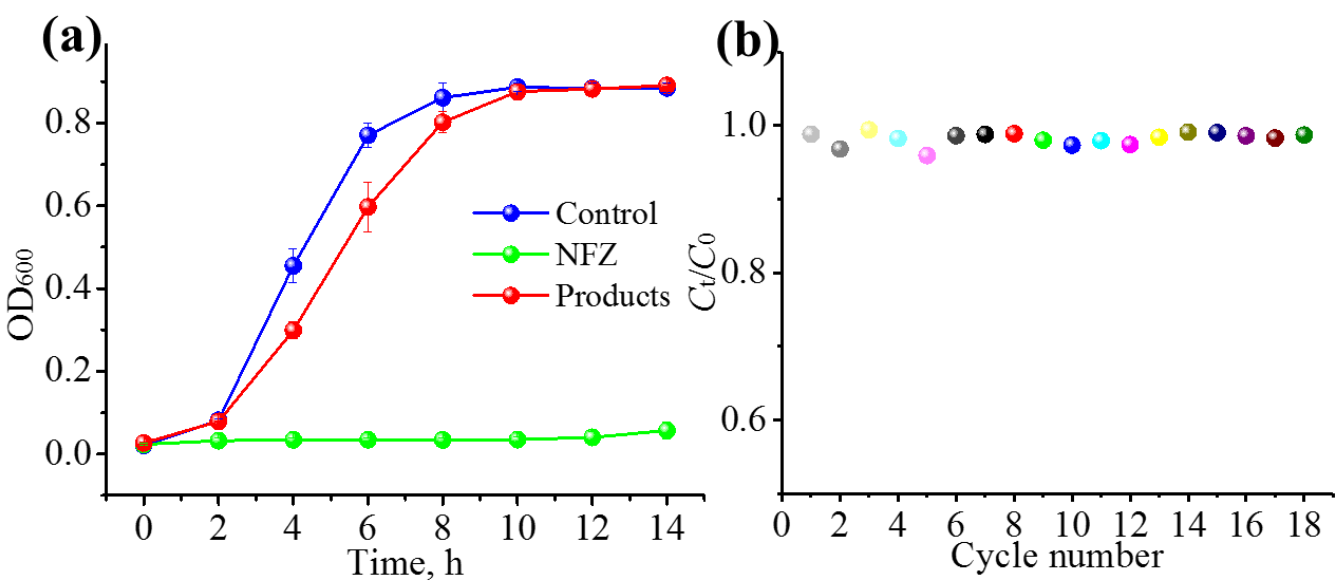

Figure 6. (a) Toxicity assessment of control, NFZ $\left(20 \mathrm{mg} \mathrm{L}^{-1}\right)$ and degradation products $(-1.25 \mathrm{Vvs}$. $\mathrm{Ag} / \mathrm{AgCl}$, $0.1 \mathrm{M} \mathrm{Na}_{2} \mathrm{SO}_{4}, 20 \mathrm{mg} \mathrm{L}^{-1} \mathrm{NFZ}, \mathrm{t}=1 \mathrm{~h}, \mathrm{pH}$ 4.28). (b) durability of GR-Ni foam electrode (-1.25 V vs. Ag/AgCl, $\left.0.1 \mathrm{M} \mathrm{Na}_{2} \mathrm{SO}_{4}, 20 \mathrm{mg} \mathrm{L}^{-1} \mathrm{NFZ}\right)$.

\section{Conclusions}

An efficient GR-Ni foam electrode was facilely prepared using one-step electrodeposition of GO suspension onto the $\mathrm{Ni}$ foam. By application of the GR-Ni foam electrode as cathode, the efficient and rapid degradation of NFZ was achieved in the electrochemical reduction process without using an expensive noble metal catalyst. The degradation rate of NFZ on the GR-Ni foam electrode was higher than that on the $\mathrm{Pd}-\mathrm{Ni}$ foam electrode, and the degradation products showed much lower antibacterial activity than the NFZ parent compound. Because of its high effectiveness and stability, low cost, and environmental friendliness, the GR-Ni foam electrode could play a beneficial role as a promising cathode in electrochemical process for efficient removal of nitrofuran antibiotics in water.

Acknowledgements: This work was supported by the National Natural Science Foundation of China (51778218 and 51478171).

\section{References}

[1] J. Davies, D. Davies, Microbiology and Molecular Biology Reviews 74(3) (2010) 417-433.

[2] S. Jechalke, H. Heuer, J. Siemens, W. Amelung, K. Smalla, Trends in Microbiology 22(9) (2014) 536545.

[3] C. Q. Gnamba, F. T. A. Appia, E. M. H. Loba, I. Sanogo, L. Ouattara, Journal of Electrochemical Science and Technology 5(2) (2015) 129-143.

[4] C. P. Andam, G. P. Fournier, J. P. Gogarten, FEMS Microbiology Reviews 35(5) (2011) 756-767.

[5] E. Marti, E. Variatza, J.L. Balcazar, Trends in Microbiology 22(1) (2014) 36-41.

[6] P. Thongsrisomboon, B. Liawruangrath, S. Liawruangrath, S. Satienperakul, Food Chemistry 123(3) (2010) 834-839.

[7] [7] A. Auro, H. Sumano, L. Ocampo, A. Barragan, The Pharmacogenomics Journal 4(1) (2004) 24-28.

[8] N. Shrivastav, B. I. Fedeles, D. Li, J. C. Delaney, L. E. Frick, J. J. Foti, G. C. Walker, J. M. Essigmann, Plos One 9(4) (2014) e94716.

[9] Y. Ni, P. Wang, S. Kokot, Biosensors and Bioelectronics 38(1) (2012) 245-251.

[10] Y. Hiraku, A. Sekine, H. Nabeshi, K. Midorikawa, M. Murata, Y. Kumagai, S. Kawanishi, Cancer Letters 215(2) (2004) 141-150.

[11] Y. Hong, X. Lin, X. Cui, L. Zhou, K. A. S. Al-Rasheid, J. Li, Ecological Indicators 54 (2015) 153-160.

[12] Y. Hong, S. Liu, X. Lin, J. Li, Z. Yi, K. A. Al-Rasheid, Environmental Science and Pollution Research International 22(12) (2015) 9544-9553. 
[13] I. Michael, L. Rizzo, C. S. McArdell, C. M. Manaia, C. Merlin, T. Schwartz, C. Dagot, D. Fatta-Kassinos, Water Research 47(3) (2013) 957-995.

[14] X. Tian, Y. Xu, X. Song, X. Gong, Y. Liu, Q. Zhou, Z. Wang, C. Xia, Marine Pollution Bulletin 112(1-2) (2016) 393-398.

[15] W.-H. Yu, T.-S. Chin, H.-T. Lai, International Biodeterioration and Biodegradation 85 (2013) 517-526.

[16] C. Ardsoongnearn, O. Boonbanlu, S. Kittijaruwattana, L. Suntornsuk, Journal of Chromatography. $B$ 945-946 (2014) 31-38.

[17] M. De Luca, S. Mas, G. Ioele, F. Oliverio, G. Ragno, R. Tauler, International Journal of Pharmaceutics 386(1-2) (2010) 99-107.

[18] B. L. Edhlund, W. A. Arnold, K. McNeill, Environmental Science and Technology 40(17) (2006) 54225427.

[19] B. Wang, X. L. Lv, D. Feng, L. H. Xie, J. Zhang, M. Li, Y. Xie, J. R. Li, H. C. Zhou, Journal of the American Chemical Society 138(19) (2016) 6204-6216.

[20] W. Y. Ying, X. Z. Hu, Journal of Dispersion Science and Technology 37(5) (2015) 613-624.

[21] Z. Z. Yuan, X. Z. Hu, Fullerenes, Nanotubes and Carbon Nanostructures 23(7) (2014) 640-648.

[22] H. Mestankova, A. M. Parker, N. Bramaz, S. Canonica, K. Schirmer, U. von Gunten, K. G. Linden, Water Research 93 (2016) 110-120.

[23] P. Liu, H. Zhang, Y. Feng, F. Yang, J. Zhang, Chemical Engineering Journal 240 (2014) 211-220.

[24] D. Kong, B. Liang, H. Yun, H. Cheng, J. Ma, M. Cui, A. Wang, N. Ren, Water Research 72 (2015) 281292.

[25] A. Rahi, N. Sattarahmady, R. Dehdari Vais, H. Heli, Sensors and Actuators B: Chemical 210 (2015) $96-$ 102.

[26] C. d. L. Brito, G. H. G. Trossini, E. I. Ferreira, M. A. La-Scalea, Journal of the Brazilian Chemical Society 24(2013) 1964-1973.

[27] W. Xie, S. Yuan, X. Mao, W. Hu, P. Liao, M. Tong, A. N. Alshawabkeh, Water Research 47(11) (2013) 3573-3582.

[28] J. Y. Lee, J. G. Lee, S. H. Lee, M. Seo, L. Piao, J. H. Bae, S. Y. Lim, Y. J. Park, T. D. Chung, Nature Communications 4 (2013) 2766.

[29] X. Zhao, M. Yin, L. Ma, L. Liang, C. Liu, J. Liao, T. Lu, W. Xing, Energy and Environmental Science 4(8) (2011) 2736.

[30] P.J. Ferreira, Y. Shao-Horn, D. Morgan, R. Makharia, S. Koch, H.A. Gasteiger, Journal of the Electrochemical Society 152(11) (2005) 65-78.

[31] L. Yang, Y. Tang, D. Yan, T. Liu, C. Liu, S. Luo, ACS Applied Materials and Interfaces 8(1) (2016) 169176.

[32] D. Li, Z. Mao, Y. Zhong, W. Huang, Y. Wu, P. Peng, Water Research 103 (2016) 1-9.

[33] D. Turcio-Ortega, D. Fan, P. G. Tratnyek, E. J. Kim, Y. S. Chang, Environmental Science and Technology 46(22) (2012) 12484-92.

[34] M. Liu, L. Yang, T. Liu, Y. Tang, S. Luo, C. Liu, Y. Zeng, Journal of Materials Chemistry A 5(18) (2017) 8608-8615.

[35] M. A. Lukowski, A. S. Daniel, F. Meng, A. Forticaux, L. Li, S. Jin, Journal of the American Chemical Society 135(28) (2013) 10274-10277.

[36] J. Heinze, Angewandte Chemie International Edition 23(11) (1984) 831-847.

[37] C. S. Reday, S. J. Reddy, Electroanalysis 4(5) (1992) 595-599.

[38] B. Liang, H. Y. Cheng, D. Y. Kong, S. H. Gao, F. Sun, D. Cui, F. Y. Kong, A. J. Zhou, W. Z. Liu, N. Q. Ren, W. M. Wu, A. J. Wang, D. J. Lee, Environmental Science and Technology 47(10) (2013) 5353-5361.

[39] A. J. Wang, H. Y. Cheng, B. Liang, N. Q. Ren, D. Cui, N. Lin, B. H. Kim, K. Rabaey, Environmental Science and Technology 45(23) (2011) 10186-10193.

[40] A. Ait Sidi Mou, A. Ouarzane, M. El Rhazi, Journal of Electrochemical Science and Engineering 7(3) (2017) 111.

[41] R. Mao, N. Li, H. Lan, X. Zhao, H. Liu, J. Qu, M. Sun, Environmental Science and Technology 50(7) (2016) 3829-37.

[42] H. Lan, R. Mao, Y. Tong, Y. Liu, H. Liu, X. An, R. Liu, Environmental Science and Technology 50(21) (2016) 11872-11878.

[43] A. Li, X. Zhao, Y. Hou, H. Liu, L. Wu, J. Qu, Applied Catalysis B: Environmental 111-112 (2012) 628-635. 
[44] S. P. Mezyk, W. J. Cooper, K. P. Madden, D. M. Bartels, Environmental Science and Technology 38(11) (2004) 3161-3167.

[45] M. Pumera, Energy and Environmental Science 4(3) (2011) 668-674.

[46] N. Park, S. Hong, G. Kim, S. H. Jhi, Journal of the American Chemical Society 129(29) (2007) 8999-9003.

[47] G. K. Dimitrakakis, E. Tylianakis, G. E. Froudakis, Nano Letters 8(10) (2008) 3166.

[48] W. C. Conner, J. L. Falconer, Chemical Reviews 95(3) (1995) 759-788.

[49] B. P. Chaplin, M. Reinhard, W. F. Schneider, C. Schuth, J. R. Shapley, T. J. Strathmann, C. J. Werth, Environmental Science and Technology 46(7) (2012) 3655-3670.

[50] B. A. Donlon, E. Razo-Flores, G. Lettinga, J. A. Field, Biotechnology and Bioengineering 51(4) (1996) 439-449.

(C2017 by the authors; licensee IAPC, Zagreb, Croatia. This article is an open-access article distributed under the terms and conditions of the Creative Commons Attribution license (http://creativecommons.org/licenses/by/4.0/) 